\title{
De mujeres y hombres: el androcentrismo en lo ambiguo
}

\author{
Natalia López-Cortés \\ Universidad de Zaragoza \\ Facultad de Filosofia y Letras \\ c/San Juan Bosco, 7 \\ 50009 Zaragoza \\ natlop@unizar.es
}

\section{DE MUJERES $Y$ HOMBRES: EL ANDROCENTRISMO EN LO} AMBIGUO

RESUMEN: El objetivo de este trabajo es presentar un análisis sobre dos palabras en español, caracterizadas por ser sustantivos ambiguos y muy frecuentes: hombre y mujer. Este estudio está enmarcado en el ámbito de las relaciones entre sociedad y lengua $\mathrm{y}$, en concreto, de las existentes entre el sistema patriarcal y la lengua española. Partiendo de este marco, se lleva a cabo el análisis del par hombre/mujer, prestando especial atención al componente de ambigüedad presente en estos nombres. Para ello, se ofrecen datos procedentes tanto de hablantes nativos del español como de diccionarios. Todo ello muestra que (i) este par de sustantivos forma una pareja asimétrica en cuanto a su significado y (ii) su ambigüedad da mucha información sobre el androcentrismo imperante en nuestra sociedad.

PALABRAS CLAVE: androcentrismo; feminismo; asimetría; significado; ambigüedad léxica.

SUMARIO: 1. Introducción: lengua y patriarcado; 2 . Androcentrismo: invisibles y olvidadas; 3 . Ambigüedad: hablantes y diccionarios; 4. El sustantivo hombres: varones y seres humanos; 5 . El sustantivo mujeres: hembras y esposas; 6 . Conclusiones.

\section{OF WOMEN AND MEN: ANDRO- CENTRISM IN AMBIGUITY}

ABSTRACT: The goal of this paper is to present an analysis on two Spanish words, both characterized for being ambiguous and very commonly used: hombre and mujer. This study takes as its starting point the relation between society and language and, specifically, the relation between patriarchal society and Spanish language. On this basis, the analysis of hombre/mujer is carried out, paying special attention to the component of ambiguity present in these nouns. Interpretation from native Spanish speakers and lexicographical information are provided. All this data shows that (i) this pair of nouns forms an asymmetric pair in terms of their meaning and (ii) their ambiguity gives a lot of information about the prevailing androcentrism in our society.

KEYWORDS: androcentrism; feminism; asymmetry; meaning; lexical ambiguity.

SUMMARY: 1. Introduction: language and the patriarchy; 2 . Androcentrism: invisible and forgotten; 3. Ambiguity: speakers and dictionaries; 4. Hombres: men and human beings; 5 . Mujeres: females and wives; 6 . Conclusions.

\section{DES HOMMES ET DES FEMMES: L'ANDROCENTRISME DANS L'AMBIGUÏTÉ}

RÉSUMÉ: L'objectif de ce travail est de présenter une analyse sur deux mots en espagnol, caractérisés par des noms ambigus et très fréquents: hombre et $m u-$ jer. Cette étude s'inscrit dans le champ des relations entre société et langue et, plus précisément, entre le patriarcat et la langue espagnole. Partant de ce cadre l'analyse du hombre/mujer est effectuée, en accordant une attention particulière à la composante d'ambiguïté présente dans ces noms. Pour cela, des données sont proposées à la fois par des hispanophones natifs et des dictionnaires. Tout cela montre que (i) cette paire de noms forme une paire asymétrique en termes de signification et (ii) leur ambiguïté donne beaucoup d'informations sur l'androcentrisme qui prévaut dans notre société.

MOTS-CLÉS: androcentrisme féminisme; asymétrie ; sens ; ambiguïté.

SOMMAIRE: 1 . Introduction: langue et patriarcat ; 2 . Androcentrisme: invisible et oublié $; 3$. Ambiguïté: locuteurs et dictionnaires ; 4. Hombres: hommes et êtres humains ; 5. Mujeres: femmes et épouses ; 6. Conclusions. 


\title{
De mujeres y hombres: el androcentrismo en lo ambiguo ${ }^{1}$
}

\author{
NATALIA LÓPEZ-CoRTÉS
}

\section{INTRODUCCIÓN: LENGUA Y PATRIARCADO}

El ser humano es, ante todo, un ser hablante: esto hace que nuestra especie sea denominada, en muchas ocasiones, no solo homo sapiens sino también homo loquens (Lorenzo y Longa, 2003). Sin embargo y aunque no nos distinga de manera tan determinante de otras especies, ya Aristóteles decía que los seres humanos somos seres sociales por naturaleza: en definitiva, somos seres hablantes que viven en sociedad.

Esta caracterización del ser humano como especie parlante, con una facultad lingüística que lo hace único, es un motivo más del interés, dentro de la teoría lingüística, en las relaciones entre lengua y sociedad: pese a que ya está demostrado que la lengua no determina cómo vemos el mundo (aunque sí influye en mecanismos como la atención o la memoria), es innegable que la lengua es una herramienta más a través de la cual nos relacionamos con lo extralingüístico y que, por tanto, se interrelaciona con nuestra experiencia vital. Esta tiene un gran componente social, puesto que vivimos en un mundo globalizado y con múltiples culturas en el que los humanos (y, por ende, los hablantes) estamos estrechamente en contacto los unos con los otros.

Para este trabajo nos interesa una parcela muy específica dentro de la enorme área de estudio de la intersección lengua y sociedad: las relaciones entre la lengua y el sistema patriarcal en el que estamos inmersos. Desde lo que se conoce como la lingüística feminista se ha intentado dar respuesta a preguntas como: ¿son las lenguas machistas?, ¿son una herramienta para la dominación?, ¿son un ejercicio de la violencia patriarcal y que, por tanto, invisibilizan a las mujeres?, entre otras muchas (para una revisión sobre el movimiento feminista, v. Varela, 2013 y sobre la lingüística feminista, v. Burgos Diaz y Aliaga Jiménez, 2002)

Sin detenernos ahora en repasar los hitos de la lingüistica feminista, es necesario entender que el contexto del que nace este estudio bebe tanto del análisis lingüístico como de premisas feministas. Una de ellas es que el androcentrismo está presente en nuestra sociedad. Este trabajo trata de reflexionar, en concreto, sobre dos sustantivos muy frecuentes en español y que son, además de ambiguos, un exponente del androcentrismo: hombre y mujer. Para ello, primero se presentará una reflexión sobre qué es el androcentrismo y como se manifiesta (lingüística y extralingüísticamente) para pasar después al análisis de la ambigüedad presente en los sustantivos hombre y mujer. En este análisis se partirá del estudio de los significados de estos sustantivos, tanto desde una perspectiva diacrónica como sincrónica. Este trabajo pretende servir de reflexión sobre cómo los hablantes expresamos nuestro machismo a la hora de hablar y a la hora de construir significados.

1 Este trabajo ha sido financiado por el Gobierno de España (FFI2017-82460-P) y el Gobierno de Aragón (Grupo Psylex H11-17R; contrato predoctoral DGA2017-2021). 
Por tanto, no estamos defendiendo que la lengua española sea machista porque entre su vocabulario se muestren, como veremos, asimetrias semánticas, sino que la lengua refleja el androcentrismo (y el machismo) en los que está imbuido nuestro modelo social. Reflexionar sobre los elementos léxicos y su organización es un punto de partida esencial para llevar a cabo un análisis de nuestras ideas preconcebidas sobre los roles de género y, posiblemente, sea más productivo que arremeter contra mecanismos gramaticales innatos y dificilmente modificables (como sucede con los estudios que tildan de machista $\mathrm{o}$, al menos, de perpetuador del machismo, el sistema gramatical de género en español, tema que sigue estando candente en los feminismos y que sigue recibiendo respuestas de varios lingüistas; v. Escandell Vidal, 2020 o Mendivil Giró, 2020, por citar los más recientes).

El léxico, al fin y al cabo, es un elemento sobre el que los hablantes podemos tomar decisiones conscientes: prueba de ello es que somos creativos y jugamos con él, como demuestran las creaciones léxicas que surgen casi a diario, atendiendo a la realidad inmediata, como covidiota o infodemia, relativas a la situación de la pandemia del COVID-19 (v. Castro, 2020 o Navarro, 2020). Los hablantes, como dice Horno Chéliz (2012), podemos elegir con qué palabras construir una oración, pero no si hacer una concordancia o no. En consecuencia, reflexionar críticamente sobre nuestro vocabulario puede ser enriquecedor y esto es, precisamente, lo que se pretende en este trabajo. Sin embargo, hemos de hacer una advertencia: intervenir en los usos léxicos androcéntricos o machistas no es suficiente para conseguir una sociedad más igualitaria. Siguiendo el ejemplo de Suardiaz (2002)2 aunque en el ámbito norteamericano se haya reflexionado mucho sobre cómo nombrar a las personas negras, el racismo no ha desaparecido. En el caso del machismo y la lengua, sabemos que la literatura al respecto es abundante y el machismo sigue estando a la orden del día.

Teniendo esto en cuenta, tomamos como punto de referencia la hipótesis de que ser conscientes de cómo las palabras perpetúan situaciones injustas (hecho que, una vez más, nada tiene ver con que la lengua sea injusta) nos puede llevar a ser igualmente más conscientes sobre la injusticia de la situación en sí. Suardiaz (2002: 145) ejemplifica esto con la palabra inglesa housewife 'ama de casa', que trasmite la idea de que solo las mujeres pueden encargarse de las tareas del hogar:

Una vez que las personas comprenden lo que implica el uso de housewife, se abre camino para que lleguen a ser conscientes - cada vez que oigan el término o se dispongan a utilizarlo - de la injusticia de la situación $n^{3}$ (no de la palabra), y para que recuerden la necesidad de cambiar dicha situación.

De hecho, Suardiaz (2002) opina que, si sustituimos esta palabra

2 La tesis de Suardiaz fue uno de los primeros trabajos sobre las relaciones entre machismo y lengua española. Se publicó por primera vez en 1973, pero para este trabajo hemos utilizado la traducción al español del 2002, llevada a cabo por José Luis Aliaga Jiménez.

3 El resaltado está presente en el texto original de Suardiaz (2002). 
por otra neutra, como housekeeper, estamos llevando a cabo un compromiso en aras de cambiar la situación extralingüística: al cambiar el léxico, nos comprometemos a cambiar lo externo a él; pero no por cambiar el léxico cambiamos la realidad. Somos conscientes de que las palabras hombre y mujer están enormemente arraigadas en nuestro vocabulario y que este trabajo no va a servir para eliminar los usos androcentristas y machistas de las mismas; pero reflexionar sobre este asunto nos puede llevar a ser más críticos con el sistema en el que vivimos y, quizá, contribuir para hacerlo más igualitario.

\section{ANDROCENTRISMO: INVISIBLES Y OLVIDADAS}

Siguiendo la metáfora de que ser feminista es ponerse unas gafas violetas, ya que "tomar conciencia de la discriminación de las mujeres supone una manera distinta de ver el mundo" (Varela, 2013: 18), podríamos decir que el androcentrismo tiene que ver con que todos llevemos puestas unas lentes opacas. La característica de esta montura androcéntrica es que sus cristales opacos, que ocultan, nos hacen ver el mundo filtrado por lo masculino. Partamos de un ejemplo, citado en Lledó (2009: 24): ¿eres capaz de resolver el acertijo que aparece en (1)?

Pérez tenía un hermano. El hermano de Pérez murió. Pero el hombre que murió no tuvo nunca un hermano.

El hecho de que nos cueste un rato darnos cuenta de que la respuesta es tan simple como que Pérez es una mujer es una prueba de que tenemos un filtro androcéntrico que nos da una visión distorsionada y parcial de la realidad. El androcentrismo es, entonces, la invisibilización sistemática de la mujer y de todo lo relativo a lo femenino. ${ }^{4}$

Es importante señalar que el androcentrismo no es una característica exclusiva de nuestra percepción lingüística, sino que está presente en nuestra sociedad de otras muchas maneras: famoso es el caso de la descripción de los sintomas de un infarto partiendo de las experiencias de los varones, sin tener en cuenta que en las mujeres se manifiestan de otra manera bien distinta. Sin embargo, es innegable que la manera en la que nombramos las cosas, el modo en el que unimos los referentes y los signos lingüísticos con los que los denotamos, tiene mucho que ver con esa visión sesgada androcéntrica; la lengua no es androcéntrica igual que no es machista, pero sí que refleja premisas androcéntricas: ¿cómo no vamos a reflejar el androcentrismo en nuestras interacciones lingüísticas si en todo momento llevamos puestas nuestras gafas opacas?

Se ha argumentado que el uso del masculino genérico en español, como en (2a), es un mecanismo gramatical que hace que prevalezca esta visión androcentrista, puesto que supone una invisibilización de lo femenino, al quedar este englobado en lo masculino. Es por esto

4 Para las diferencias con respecto al machismo y la misoginia, v. Lledó (2009). También es interesante el concepto de "ginopia" (Campagnoli, 2015) 
que desde la lingüística feminista se han propuesto diferentes alternativas para eliminar (o reducir) el uso del masculino genérico, como el uso de sustantivos neutros (2b), nombres colectivos (2c), desdoblamientos (2d) o incluso el uso del femenino como género inclusivo (2e).
a. Todos los alumnos tienen que presentarse al examen.
b. Todos los estudiantes tienen que presentarse al examen.
c. Todo el estudiantado tiene que presentarse al examen.
d. Todos los alumnos y las alumnas tienes que presentarse al examen.
e. Todas las alumnas tienen que presentarse al examen.

No vamos a detenernos ahora sobre este debate, pero desde una perspectiva lingüística, consideramos que la percepción de que existe androcentrismo en el masculino genérico viene dada por una confusión entre la referencia a informaciones conceptuales semánticas y el uso de morfemas de expresión de género gramatical. Por tanto, consideramos que el mecanismo del masculino genérico no es en sí un mecanismo invisibilizador, aunque el hecho de que haya colectivos que asi lo perciban puede ser un punto de partida para una reflexión critica sobre este asunto (que, por otro lado, habría de pasar por la recogida de datos empíricos ${ }^{5}$ sobre los que poder establecer hipótesis válidas, como menciona Bengoechea Bartolomé, 2015). De hecho, una prueba de que el androcentrismo va mucho más allá del género gramatical es que, al leer las oraciones de (3) (extraidas de Mendivil Giró, 2020), pensemos en referentes masculinos, pese a tratarse de sustantivos femeninos:

a. La autoridad competente tomará las medidas oportunas

b. Fue operado por una eminencia

Tal y como hemos mencionado en la sección anterior, consideramos especialmente interesante reflexionar sobre cómo el léxico y los significados interaccionan con el androcentrismo, al tener estos un carácter mucho más propenso al cambio que los mecanismos gramaticales. ${ }^{6}$ Para reflexionar sobre el vocabulario, es esencial introducir el concepto de asimetría que, como veremos, está muy presente en la pareja de sustantivos hombre y mujer. Además, se puede afirmar con rotundidad que las asimetrias son una clara muestra de sexismo lingüístico, en tanto que transmiten una desigualdad en el significado denotativo en dependencia del sexo del referente al que se apliquen. El estudio pionero sobre sexismo en español ya puso de relieve este problema (Suardiaz, 2002).

Asi, supone una asimetria que existan distintos significados para una misma palabra según si se aplican a un referente masculino o femenino, como sucede en los pares zorro/zorra, lagarto/lagarta o gobernante/go-

5 Existen estudios experimentales sobre el procesamiento y la adquisición del género gramatical, como el de Ogneva (en prensa) pero, al menos hasta donde llega nuestro conocimiento, no se han hecho investigaciones teniendo en cuenta el sexo de los participantes como variable de estudio, idea que plantea Bengoechea Bartolomé (2015) como línea de investigación todavía abierta.

6 No negamos que estos puedan cambiar, pero estos cambios serán mucho más lentos. 
bernanta. No siempre el cambio de significado implica un cambio morfológico: por ejemplo, el adjetivo inocente tiene una connotación diferente según se refiera a hombres ('no culpable', 'ingenuo') o a mujeres ('virgen').

Hay usos de este estilo que ya se han dejado atrás, como el interpretar el femenino jueza con el significado de 'mujer del juez'. Esto es prueba de que hay usos androcéntricos que efectivamente pueden superarse. En el trabajo de Suardiaz (2002) se ejemplifica un caso de asimetría, que denomina "vacío léxico", con el par ama de casa/amo de casa: en el momento de la presentación de la tesis de Suardiaz (el año 1973) la forma masculina no existía, mientras que hoy en día es de uso extendido; por ejemplo, el Pais Semanal publicó este mismo año un artículo titulado: "De profesión, amo de casa".7

Como ya hemos mencionado, la visión androcentrista no la encontramos solo en las asimetrias de significado y de uso, sino que está presente en nuestra conceptualización del mundo. Lleva las gafas androcéntricas quien escribe oraciones como las recogidas en (5), donde o bien se nombra a la mujer en relación a un hombre (a veces citando su nombre, como en $5 \mathrm{a}$, a veces no, como en $5 b)$, o bien solo se las identifica con el sustantivo mujer (5c):

a. Siri Hustvedt. La mujer de Paul Auster y su aclamada novela sobre machismo en el arte ${ }^{8}$

b. El pelo en los brazos está de moda: lo dice la novia de Brooklyn Beckham ${ }^{9}$

c. Una mujer gana por primera vez el 'Nobel' de matemáticas ${ }^{10}$

Todos estos fragmentos están extraídos de medios periodísticos publicados el año pasado. Sin embargo, esta manera de percibir a las mujeres, de representarlas y nombrarlas no es algo nuevo. La aclamada novela de Clarín, publicada en 1884, se titula La Regenta porque la protagonista está casada con el exregente de la audiencia. En un museo asturiano se expone un cuadro del año 1857 titulado Antonio Jaspe Moscosa y su hermana: aunque ambos están retratados, solo se identifica al varón. ${ }^{11}$

Nombrar es un mecanismo esencial, porque los seres humanos somos "primates semióticos por excelencia" (Horno Chéliz, 2018). Parece que si algo no se nombra, no existe. Tener una palabra para nombrar algo legitima el concepto al que esa palabra se refiere (Bengoechea Bartolomé, 2015). Por ello, hemos de nombrar lo femenino. Superar el androcentrismo y quitarnos las gafas opacas significaría superar la identificación de la mujer como, en palabras de Simone de Beauvoir (2005 [1949]), "el segundo sexo" o "lo otro".

\footnotetext{
7 https://www.amosdecasa.com/leer/de-profesion-amo-de-casa. 8 https://twitter.com/porliniers/status/1131610456995618816/photo/1. 9 https://smoda.elpais.com/celebrities/la-novia-de-brooklyn-beckham-ficha-porinditex-y-presume-de-vello-en-los-brazos/.

10 https://elpais.com/elpais/2019/03/19/ciencia/1552992900_461327.html

$11 \mathrm{http}: / /$ ceres.mcu.es / pages / ResultSearch?txtSimpleSearch=Antonio\% 20 $\mathrm{J}$ a s p e \% $20 \mathrm{M}$ o s c o s o \% 20 y $\% 20 \mathrm{~s} \mathrm{u} \% 20 \mathrm{~h}$ e rman a \% 20 ni $\%$ F 1 os \&simpleSearch=0\&hipertextSearch=1\&search=simple\&Museums Search$=\&$ MuseumsRolSearch=1\&listaMuseos=null.
} 


\section{AmbigüEdad: hablantes y Diccionarios}

Puesto que el análisis presentado en los apartados 4 y 5 sobre los sustantivos hombre y mujer y su sesgo androcéntrico parte del hecho de que esos sustantivos son ambiguos, en este apartado se va a repasar brevemente qué es la ambigüedad léxica y cómo se puede estudiar. La ambigüedad está presente de manera constante en nuestra lengua. Muchas de las palabras que utilizamos pueden significar varias cosas $\mathrm{y}$, aunque a niveles de procesamiento se encuentre un efecto de la ambigüedad, somos capaces de comunicarnos día a día sin ningún tipo de problema. La ambigüedad léxica, entendida como el hecho de que una única palabra puede transmitir múltiples significados, relacionados o no entre sí, no solo existe en español, sino que es una propiedad universal: varios autores creen que la ambigüedad es una propiedad esencial a la hora de organizar nuestro lexicón mental, puesto que nos permite poner en relación unidades léxicas que, de otra manera, estarian desconectadas entre sí: por tanto, la ambigüedad cohesiona el sistema lingüístico y, gracias a que somos capaces de desambiguar, no nos da problemas a la hora de comunicarnos (López-Cortés, 2020a; Stella et al., 2018).

Reflexionar sobre la ambigüedad léxica puede ayudarnos a entender de dónde surgen las palabras y sus significados: los mecanismos de creación semántica están estrechamente ligados con la polisemia. Además de darnos pistas sobre el origen y la evolución de las unidades léxicas, y de la consecuente estructuración de nuestro lexicón mental, la ambigüedad también nos puede hacer reflexionar sobre cómo nosotros, como hablantes, entendemos el mundo. Un ejemplo de esto es el hecho de que, como sostienen las teorías cognitivistas, conceptualicemos lo que nos rodea partiendo de nuestra propia experiencia (Ibarretxe-Antuñano, 2018): esto explicaría que el dominio origen de varias metáforas muy productivas en español (y en otras lenguas) tengan que ver con las partes del cuerpo. De esta manera, el corazón puede ser el 'órgano vital' (6a) pero también el 'núcleo de un asunto (6b)', o la cabeza se puede referir a la 'parte del cuerpo' (6c) pero también a la 'primera posición' (6d):

(6) a. Una vida sedentaria puede ser una causa de ataques al corazón.

b. La historia de este personaje es el corazón del libro.

c. Tras el accidente tenía siempre mucho dolor de cabeza.

d. Esa farmacéutica está a la cabeza en el desarrollo de la vacuna.

Todo esto implica que nuestra interacción con el medio (y, por ende, con lo social) se verá reflejado en la lengua y en cómo hablamos: los diferentes significados que una palabra ha ido adquiriendo a lo largo de la historia serán más o menos frecuentes según nuestras necesidades comunicativas. Partamos de un ejemplo: la palabra lata, en español, puede significar, entre otras cosas, 'algo aburrido, pesado' 
(7a). Este último significado proviene de un significado anterior, "palo o vara larga' (7b), del que surge la expresión dar la lata (7c). La realidad extralingüística, en la que el uso del referente de 'palo o vara larga' ha quedado obsoleto, ha hecho que un significado, pese a ser el original, se pierda y, sin embargo, que su significado extendido triunfe. De esta manera, un significado que era secundario gana terreno a otro.

a. Menuda lata tener que volver a clase.

b. Empezaron a sacudirnos el polvo con palos y latas (ejemplo adaptado del Diccionario crítico-etimológico castellano e hispano; en adelante $D C E C H$ ).

c. Mi hermano pequeño siempre está dando la lata.

Lo mismo ocurre, por ejemplo, con la palabra disco: el significado original de 'objeto deportivo' (8a) es mucho menos frecuente que el de 'objeto para almacenar' (8b) y esto no responde a una necesidad del sistema lingüístico sino al uso que nosotros le damos como hablantes para relacionarnos con el medio que nos rodea: en otras palabras, la evolución histórica de las ambigüedades no correlaciona con la frecuencia de uso de sus diferentes significados en la actualidad (Haro et al., 2017; López Cortés, 2019); ese uso viene favorecido por otros factores.

(8) a. Se ha batido el récord en lanzamiento de disco.

b. El grupo revelación de la temporada ha sacado un nuevo disco.

Existen, por tanto, dos opciones a la hora de estudiar los distintos significados de una palabra ambigua: cómo han surgido históricamente y cómo se interpretan en la actualidad por los hablantes. Estas dos aproximaciones siguen, así, la clásica oposición entre sincronía y diacronia, establecida por Saussure (1987 [1916]). La interpretación que los hablantes hacen de la ambigüedad (es decir, la interpretación sincrónica) viene dada, como hemos mencionado antes, por el uso que les dan a sus significados y la relevancia que estos tienen en nuestra sociedad. Esto ha hecho, por ejemplo, que uno de los significados más frecuentes de la palabra perfil sea 'de las redes sociales' (9a), un significado inexistente hace unas décadas. O, en casos más específicos todavía, que al leer marca (9b) o fila (9c) los hablantes recuperen los referentes de un periódico o unas deportivas.

(9) a. Todos los días actualizo mi perfil de Instagram.

b. Marca es uno de los periódicos más vendidos.

c. Mi hija dice que quiere comprarse unas fila.

Es a la hora de estudiar esta interpretación sincrónica de la ambigüedad léxica cuando surge la motivación para el análisis de los sustantivos hombre y mujer, ya que ambos son percibidos como ambiguos y esta ambigüedad es asimétrica: los significados que se recuperan son de un carácter totalmente distinto. 
Los datos sobre los sustantivos mujer y hombre, en los que se basa este estudio, han sido extraidos del corpus de López-Cortés (2020b), caracterizado por presentar datos subjetivos sobre la interpretación de la ambigüedad léxica. Las palabras ambiguas recogidas en este corpus están clasificadas como tales partiendo de la interpretación subjetiva que de ellas hacen hablantes nativos del español: a través de una serie de cuestionarios, se preguntaba a los participantes si las distintas unidades léxicas tenían uno o varios significados y se les pedía que escribieran los significados que conocieran de las diferentes palabras.

Se va a recurrir también a lo que se recoge en el Diccionario de la Real Academia Española (en adelante, $D L E$ ), en su última versión online, en lo relativo a los sustantivos hombres y mujer. El objetivo de esto es contrastar lo que aparece recogido en las entradas lexicográficas y lo que los hablantes de español recuperan a través de pruebas de elicitación, como las de López-Cortés (2020b). Tal y como han demostrado varios autores, la interpretación subjetiva de la ambigüedad no correlaciona con la historia etimológica de las unidades léxicas. Por ello, este estudio lexicográfico de una de las obras de consulta más famosas en español nos puede dar información sobre las diferencias entre el conocimiento semántico "institucionalizado" y el interiorizado y comprobar si existe alguna diferencia. Por otro lado, el estudio de lo recogido en el diccionario continua con la tradición de la crítica feminista a la lexicografia (v. Lledó et al., 2004).

Además de esta aproximación sincrónica a ambos sustantivos, creemos que es necesario tener una perspectiva histórica que dé cuenta de cómo se ha llegado a la creación y la interpretación de los significados actuales: esto es, los significados no surgen de la nada, sino que vienen motivados o bien por el sistema lingüístico o bien por la realidad extralingüistica. Es precisamente este filtro cultural, social e incluso político el que nos interesa a la hora de estudiar esta pareja de sustantivos: un estudio diacrónico de estas palabras nos aportará información sobre cómo se ha ido configurando la información hoy presente en el imaginario colectivo ${ }^{12}$. Esto es además especialmente interesante si consideramos que el androcentrismo (y su reflejo en la lengua) no es, precisamente, un fenómeno reciente. Por ello, se revisará también el DCECH.

Con este análisis se combinará, entonces, una aproximación sincrónica y diacrónica al estudio de las unidades léxicas ambiguas hombre y mujer y se verá cómo la ambigüedad favorece el androcentrismo, invisibilizando lo femenino y estableciendo al varón como la medida de todas las cosas.

\section{El SUSTANTIVO HOMBRE: VARONES Y SERES HUMANOS}

El sustantivo hombre es clasificado como ambiguo en el corpus de López-Cortés (2020b) con un porcentaje de acuerdo del 73,2 \% (lo que quiere decir que más del $70 \%$ de los participantes interpreta que esta palabra tiene más de un significado). En el corpus se recuperan dos

12 Este recorrido histórico se ha hecho en otras ocasiones con otras palabras relevantes como árbitra o portavoza (Albitre, 2021). 
significados diferentes del sustantivo hombre: 'varón' (10a) y 'conjunto de personas' (10b).

(10) a. Hoy he conocido a un hombre muy simpático.

b. Este ha sido un pequeño paso para el hombre, pero un gran paso para la humanidad.

Por tanto, se puede afirmar que el sustantivo hombre tiene un significado específico, referido a los miembros varones de nuestra especie, y otro más amplio, referido a todo el conjunto de seres humanos: en este último, por tanto, se engloba a las mujeres.

El primer significado de hombre ('varón') se recupera por el 83,93 $\%$ de los participantes mientras que el segundo ('conjunto de personas'), por un 53,57 \%; el significado de 'varón' parece más accesible y frecuente para los hablantes nativos de español. Esto implica que una lectura "genérica" del sustantivo hombre tendría que ser más costosa que la lectura especifica de hombre como 'varón', ya que la frecuencia es una variable que interactúa directamente con el procesamiento: cuanto más frecuente es un significado, más fácilmente se accede a él y, por tanto, menos carga cognitiva conlleva su procesamiento

Sin embargo, el DLE ordena las acepciones de la palabra hombre partiendo del significado genérico para llegar al significado de 'varón', como se puede comprobar en la Figura 1. El criterio que sigue el DLE es presentar primero las acepciones no marcadas (es decir, aquellas que no llevan etiquetas como en desuso, coloquial o referentes a variedades diatópicas); como ambos significados son iguales en ese sentido, lo lógico sería pensar que dentro de la entrada se van a ordenar siguiendo un criterio de frecuencia de uso (v. Gargallo Gil, 1992 y Rodríguez Díez, 2003, para una reflexión crítica al respecto). Aunque el $D L E$ no explica qué criterios concretos se siguen para ordenar las entradas sin marca, sí que dice lo siguiente: "la lógica puede imponer cambios también en esta ordenación. En el artículo ángulo, por ejemplo, la acepción con marca de geometría va antepuesta a las correspondientes a 'rincón', 'esquina' y 'punto de vista', sentidos derivados del anterior, pero que no necesitan marca de ningún tipo"13. 


\section{hombre}

Del lat. homo, -innis.

1. m. Ser animado racional, varón o mujer. El hombre prehistórico.

2. m. varón (\| persona del sexo masculino).

3. $m$. Varón que ha llegado a la edad adulta.

4. m. Varón que tiene las cualidades consideradas masculinas por excelencia. iEse si que es un hombrel U. t. c. adj. Muy hombre.

5. m. coloq. Marido o pareja masculina habitual, con relación al otro miembro de la pareja.

Figura 1: Entrada de hombre en el DLE

Por consiguiente, la impresión que tenemos al leer una entrada como la de hombre es que la acepción 1 es la más frecuente y de uso más común. Esta presentación no es coherente con los datos empíricos recogidos en el corpus (López-Cortés, 2020b), ya que hemos visto que la tendencia de interpretación de los significados se da justo al revés. Siguiendo la línea de esta misma idea, también tendría sentido ordenar los significados atendiendo a su concreción, partiendo del significado más concreto ('varón') al más abstracto ('ser humano') ${ }^{14}$.

La pregunta pertinente es si el sustantivo hombre engloba realmente a las mujeres. Es buen momento para detenernos a reflexionar sobre el hecho de que el significado se construye: así como hemos dicho que los mecanismos gramaticales son mucho más complejos de modificar, porque van ligados a la configuración más abstracta del sistema lingüístico, el significado varía, cambia, se adapta a nuestras circunstancias extralingüisticas. Por ejemplo, el verbo tuitear no existía hace dos décadas o, como hemos visto con las palabras ambiguas, el significado original en varias ocasiones se ha perdido y perviven significados que en su momento fueron metafóricos o secundarios.

Retomando el tema de la ambigüedad: ¿qué hace que una palabra genere un nuevo significado ${ }^{15}$ La necesidad de nombrar algo y el espacio de almacenamiento limitado del léxico del que disponemos: cuando se tiene que dar nombre a algo nuevo, es mucho más económico a nivel cognitivo reutilizar una unidad léxica ya disponible (Piantadosi et al., 2012, López-Cortés 2020a), por eso llamamos ventana a la visualización de los programas del ordenador y no ha surgido una

14 El corpus de López-Cortés (2020b) presenta también datos relativos a la imaginabilidad de cada uno de los significados ambiguos: el significado de 'varón' obtiene una puntuación de imaginabilidad mayor que el de 'conjunto de personas', por lo que se puede afirmar que es más concreto.

15 Se esté dejando de lado el fenómeno de la homonimia, otro tipo de ambigüedad cuyo proceso de formación es totalmente diferente. 
palabra nueva, que tendriamos que aprender de cero. Sin embargo, con el sustantivo hombre no se da este proceso. El significado del sustantivo hombre surge para detonar una realidad ajena a la lengua: a los seres humanos varones (v. $D C E C H$ ). Desde ahí, se generaliza para nombrar al conjunto de seres humanos, probablemente, como apunta Bengoechea Bartolomé (2015) por el hecho de que todos aquello que permitía la estabilización de la lengua y sus significados hace siglos, como las leyes o los documentos administrativos, estaba vetado para las mujeres y, por tanto, no era necesario nombrarlas ni incluirlas.

Este proceso lingüístico es el mismo que encontramos en otra palabra del mismo corpus: tierra con los significados de 'suelo' (11a) y 'planeta' (11b).

$$
\begin{aligned}
& \text { a. Después de la lluvia, el suelo estaba lleno de tierra } \\
& \text { y barro. } \\
& \text { b. La Tierra es el único planeta que tiene una única } \\
& \text { luna. }
\end{aligned}
$$

Ambos sustantivos parecen reflejar una especie de relación de hiper/hiponimia, en la que uno de los significados ('varón'/'suelo') incluye al otro ('personas'/'tierra'). Así, uno de los significados actúa como una suerte de prototipo de una categoria. Esto es especialmente interesante en el caso de la palabra hombre, por las consecuencias extralingüísticas que tiene el considerar al varón como prototipo del conjunto de seres humanos. Es por esto que el nombrar al conjunto de seres humanos como hombres no viene dado por un proceso de generación normal de la ambigüedad sino a raíz de un sesgo androcentrista: se denota a los varones y más adelante, a partir de cambios sociales como, por ejemplo, el movimiento sufragista o la incorporación de las mujeres a la vida laboral, se incluye a las mujeres en ese grupo y en esa expresión lingüística.

El uso de hombre como nombre genérico puede parecer a simple vista un hecho reducido pero aun a día de hoy está presente en nuestra sociedad. El año pasado una marca de coches utilizó en un anuncio la siguiente expresión: "El primer hombre que caminará sobre Marte ya ha nacido". ${ }^{16}$ Este uso, aunque se podría justificar precisamente en la ambigüedad del sustantivo, es cuanto menos contraproducente, puesto que, como demuestran los datos empíricos citados más arriba, el significado excluyente de 'varón' es recuperado mucho más frecuentemente por los hablantes. Si el significado más común fuera, realmente, el de 'ser humano' no deberia haber ningún problema para utilizar cualquiera de las colocaciones que aparecen en el $D L E$ para referirnos a mujeres:

(12) a. Juan es un hombre público / *Juana es un hombre público b. Juan es un hombre orquesta / *Juana es un hombre orquesta

De hecho, el asunto sobrepasa al sustantivo hombre para varias au- 
toras, que argumentan que palabras como homicidio o hominido también se han construido partiendo de ese sesgo androcentrista (Suardiaz, 2002). Además, esta ambigüedad se da todavía más claramente en inglés, con los sustantivos formados sobre man (como fireman o policeman), que en los últimos años han venido sustituyéndose por otros más inclusivos. Mención aparte merece el sustantivo mankind, que para algunas autoras feministas (Miller y Swift, 1972) deberia ser sustituido por genkind (aun existiendo humankind, como bien señala Suardiaz, 2002).

De cualquier manera, sirvan estas reflexiones para darnos cuenta de que la construcción de los significados (y, por ende, la creación de las ambigüedades) tiene mucho que ver con la realidad en la que vivimos. Como dice Lledó (2009: 18):

Saber que existen las palabras persona y ser humano hace que la elección de la palabra hombre como falsa alternativa para denominar a la humanidad ponga de manifiesto que la lengua no obliga a hacerlo de este modo, sino que se trata de una elección ideológica.

\section{El SUSTANTIVO MUJER: HEMBRAS Y ESPOSAS}

Los datos del corpus de López-Cortés (2020b) resultan curiosos en un primer momento: el sustantivo mujer se interpreta por los hablantes como monosémico, es decir, como una palabra con un único significado. De hecho, tan solo un $17,20 \%$ de los participantes marcan la respuesta relativa a que perciben más de un significado. Sin embargo, podemos afirmar que existen dos significados diferentes: 'persona de sexo femenino' (13a) y 'esposa' (13b) ${ }^{17}$.

a. Esta clase de baile es solo para mujeres

b. La mujer de mi amigo se ha puesto enferma

Al comparar esto con el sustantivo hombre, ya aparecen varias asimetrias de significado. En primer lugar, el sustantivo mujer tiene un significado extra relativo al estado civil, no presente en el sustantivo hombre ${ }^{18}(14 \mathrm{a})$. Desde el punto de vista contrario, el sustantivo mujer carece del carácter genérico de hombre (14b). Además, si antes definiamos uno de los significados de hombre como 'varón', no encontramos un sustantivo que recoja esta información referida a lo femenino (14c); la otra opción, compuesta por el par hembra-varón también muestra asimetria, ya que hembra puede utilizarse para referirse a cualquier ser animado, pero no varón, ya que esta información se nombra con un sustantivo diferente, macho (14d).

a. Os declaro marido y mujer / ?Os declaro hombre y mujer.

17 Mención aparte merece la historia etimológica del sustantivo esposa, también ambiguo (v. Corominas y Pascual, 1980).

18 Como se puede comprobar en la Figura 1, el DLE recoge esta acepción, pero creemos que su uso es excesivamente específico, al contrario de lo que sucede con mujer. Compárese: Esta es mi mujer/Este es mi marido/?Este es mi hombre, en donde el significado de hombre adquiere otro matiz. 
b. El origen del hombre tuvo lugar hace millones de años / ?El origen de la mujer tuvo lugar hace millones de años.

c. Les gustaría tener un varón /?Les gustaria tener una hembra. d. Una ballena macho pesa toneladas / *Una ballena varón pesa toneladas.

Tanto en el $D L E$ como en el $D C E C H$ se recogen estos dos significados, como se muestra en las Figuras 2 y 3 respectivamente.

\section{mujer}

Del lat. mulier, -êris.

1. f. Persona del sexo femenino.

2. f. mujer que ha llegado a la edad adulta.

3. f. mujer que tiene las cualidades consideradas femeninas por excelencia. iEsa si que es una mujerl U. t. c. adj. Muy mujer.

4. f. Esposa o pareja femenina habitual, con relación al otro miembro de la pareja.

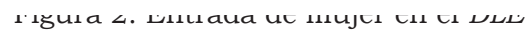

MUJER, del lat. MŬLIER, -ĔRIS, id. $1^{a}$ doc.: orígenes del idioma (muller, doc. arag. de 1025; mugier, doc. de 1113, Cid, etc.; muger, doc. de 1194, Oelschl.).

De uso general en todas las épocas y común a todos los romances; pero fuera del castellano, el portugués y el rumano, ha quedado reducido en todas partes al sentido de 'esposa', mientras que en el etimológico lo han reemplazado FEMINA - DOMINA. En latín vulgar se pronunciaría MU-

Figura 3: Entrada de mujer en DCECH

Estas asimetrías nos dicen mucho sobre la conceptualización de lo femenino en nuestra lengua y además explican, en gran medida, la interpretación subjetiva del sustantivo mujer como un caso de monosemia. Esto parece indicar que la identidad de la mujer está constituida en base a su papel en el matrimonio ${ }^{19} \mathrm{y}$, por tanto, en dependencia al

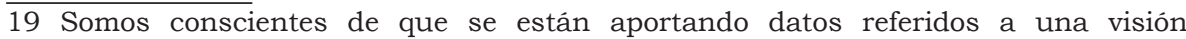


hombre: "el empleo de mujer para significar 'esposa' sugiere que la persona en su totalidad se encuentra involucrada en el matrimonio. Ella no es la mujer de (alguien) y otra cosa al mismo tiempo: ser mujer de 'esposa' conforma su identidad por completo" (Suardiaz, 2020: 176).

Por tanto, esto explica los datos relativos a interpretar el sustantivo mujer como una palabra con un único significado, ya que, aunque amalgame bajo una única forma matices de significado diferentes, ambos están tan estrechamente ligados que no se separan (como sí que ocurría con hombre). Esto no quiere decir que seamos machistas por utilizar el sustantivo mujer, pero, como venimos defendiendo a lo largo de todo el trabajo, un análisis de las construcciones de significado nos puede hacer reflexionar sobre el androcentrismo presente en nuestra sociedad.

Suardiaz (2002) reflexiona, además, sobre el uso del posesivo con el sustantivo de mujer. Según esta autora, para marcar el significado de 'esposa' es necesario usar un posesivo, puesto que esta lectura no es posible sin él (no sin más información contextual). Sin embargo, marido sí que puede utilizarse sin ser precedido por un posesivo. Aunque los ejemplos de (15) puedan ser algo forzados, sirven para mostrar que en el caso de (15a), la eliminación del posesivo resulta en una oración dificil de interpretar, precisamente porque surge ambigüedad entre los dos significados posibles, mientras que esto no sucede en (15b). Todo esto parece reforzar la idea de que "estar casado" es una característica accidental de los hombres mientras que esa misma característica, para las mujeres, resulta inherente e identitaria.

(14) a. [En una conversación entre hombres casados] Nuestras mujeres han quedado mañana / ? Las mujeres han quedado mañana.

b. [En una conversación entre mujeres casadas] Nuestros maridos han quedado mañana / Los maridos han quedado mañana.

Además de los significados del sustantivo mujer, resulta también pertinente estudiar las diferentes colocaciones que aparecen en el DLE: de nueve que se recogen en la entrada de mujer, cuatro son sinónimos de prostituta (de la calle, del partido, mundana, pública), dos hacen referencia a caracteristicas fisicas o sexuales (fatal, objeto) y una a las labores domésticas (de gobierno). Por tanto, de las nueve colocaciones recogidas solo dos no tienen que ver con estereotipos de género o con el sexo; por el contrario, de las veinte colocaciones de la entrada de hombre (como vemos, sustantivo mucho más versátil), solo una hace referencia a la apreciación del aspecto físico o sexual masculino (hombre objeto).

Aparecen, además, varias asimetrias que merece la pena reseñar; por ejemplo, las diferencias entre las definiciones de mujer pública y hombre público (Figura 4) o la acepción extra que tiene mujer de la calle (Figura 5).

cisheteropatriarcal de la realidad; pero precisamente por ser ésta la visión más extendida es la que nos interesa para este análisis. 


\section{hombre público}

1. $m$. hombre que tiene presencia e influjo en la vida social.

\section{mujer pública}

\section{I. f. prostituta.}

Figura 4: Para hombre público/mujer pública en el DLE

\section{hombre de la calle}

1. m. Persona normal y corriente.

\section{mujer de la calle}

1. f. mujer normal y corriente.

2. f. Prostituta que busca a sus clientes en la calle.

Figura 5. Para hombre de la calle/mujer de la calle en el DLE

Además, también aparecen asimetrias en los usos metafóricos de estos sustantivos, como se recoge en las expresiones de (16), que cuando se aplican a un hombre tienen una connotación positiva, relativa a la madurez personal o los éxitos profesionales (16a), mientras que cuando se utiliza para hablar de las mujeres hacen referencia a un hecho biológico, relacionado en gran medida con la sexualidad (16b).

(16) a. Ha conseguido su primer trabajo: se ha hecho hombre.

b. Le ha venido la regla: se ha hecho mujer.

Todos los datos presentados en este apartado indican que la construcción del significado de mujer se basa o bien en su diferencia con respecto a los varones (al no poder obtener carácter genérico) o bien en su rol social inferior (adquirido mediante el matrimonio o mediante su aspecto físico y atributos sexuales).

\section{Conclusiones}

Queremos acabar este trabajo volviendo al tema de la ambigüedad, ya que nos encontramos ante dos sustantivos peculiares: uno que es ambiguo y no "deberia" serlo (hombre) y otro que, aunque ambiguo, es percibido como monosémico y “debería” separar tajantemente sus significados (mujer). En el caso de hombre utilizamos un significado ('varón') como prototipo para describir a toda la humanidad, generando lo que podemos llamar una falsa ambigüedad, resultante de siglos y siglos de visión androcentrista. Lo ideal sería que todos fuéramos conscientes de esto y rompiéramos, en la medida de lo posible, con esta ambigüedad, utilizando para denotar al conjunto de hombres y mujeres otros términos verdaderamente genéricos como personas o seres humanos. En el 
caso del sustantivo mujer nos encontramos con dos significados muy diferentes ('persona de sexo femenino' y 'esposa') bajo una única forma léxica, que además es percibida como monosémica. Puesto que no todas las mujeres han de ser necesariamente esposas, una posibilidad sería utilizar otra palabra para desligar ambos significados: tenemos varias posibles candidatas como esposa, pareja, consorte o cónyuge ${ }^{20}$.

Esto no puede considerarse como una imposición porque sabemos que los cambios lingüísticos, incluso los más flexibles como los relativos al léxico, no suceden de un día para otro y conllevan, en la mayoría de los casos, un uso generalizado por parte de la población. Por otro lado, el objetivo de este trabajo no es cambiar la manera en la que hablamos sino ofrecer una reflexión que pueda enriquecer nuestra conciencia feminista, exponiendo que la ambigüedad esconde, al igual que otros fenómenos lingüísticos, sesgos androcéntricos que han de sacarse a la luz.

\section{REFERENCIAS}

ALIBTRE, P. (2021): "La lengua ante una nueva realidad social de la mujer: construcción del género en portavoza y árbitra". Revista De Filología Y Lingüistica De La Universidad De Costa Rica, 47(2), e46767.

BEAUVOIR, S. de (2005 [1949]): El segundo sexo. Madrid: Cátedra.

BENGOECHEA BARTOLOMÉ, M. (2015): Lengua y género, Madrid: Sintesis.

BURGOS DÍAZ, E. \& ALIAGA JIMÉNEZ, J. L. (2002): "Estudio preliminar", Suardiaz, D. E.: El sexismo en la lengua española, Zaragoza: Libros Pórtico, pp. 15-107.

CAMPAGNOLI, M. A. (2015): “iAndá a lavar los platos! Androcentrismo y sexismo en el lenguaje", Bach, A. M. (coord.): Para una didáctica con perspectiva de género, Buenos Aires: Miño y Dávila.

CASTRO, X. (2020): "Sinfinamiento, cuarentenials... El neoléxico de la pandemia", Archiletras, 8, pp. 32-38.

[DCECH] COROMINAS, J. \& PASCUAL, J. A. (1980): Diccionario crítico etimológico castellano e hispánico, Madrid: Gredos.

$[D L E]$ REAL ACADEMIA ESPAÑOLA (2018): Diccionario de la lengua española (versión electrónica 23.2). Disponible en http: / / www.rae.es/rae.html.

ESCANDELL VIDAL, M. V. (2020): "En torno al género inclusivo", IgualdadES, 2, pp. 223-249. https://doi.org/10.18042/cepc/ IgdES.2.08.

GARGALLO GIL, J. E. (1992): "La ordenación de acepciones en algunos artículos lexicográficos del DRAE: cuestiones de norma y uso", Actas del II Congreso Internacional de Historia de la Lengua española, 1, pp. 1043-1054.

HARO, J., FERRE, P., BOADA R. \& DEMESTRE J. (2017): "Semantic ambigutiy norms for 530 Spanish words", Applied Psycholinguistics, 38(2), pp. 457475. https://doi.org/10.1017/ S0142716416000266.

HORNO CHÉLIZ, M. C. (2012): "Los lingüistas y el traje nuevo del emperador", Letras Libres. Disponible en: https://www. letraslibres.com/mexico-es-

20 A modo de anécdota, se refleja aquí que algunos hablantes de otras lenguas han preguntado en foros sobre la posibilidad de utilizar marida como término opuesto a marido, como se puede comprobar en https://spanish.stackexchange.com/ questions / $17417 /$ is-it-possible-to-refer-to-a-wife-as-una-marida. Además, tal y como comenta un usuario de ese mismo foro, el término marida aparece en una novela de Cervantes precisamente con ese significado. 
pana/los-linguistas-y-el-traje-nuevo-del-emperador.

HORNO CHÉLIZ, M. C. (2018): "Bondades, peligros y redundancias del lenguaje inclusivo", Letras Libres. Disponible en: https://www.letraslibres.com/ espana-mexico/cultura/bondades-peligros-y-redundancias-del-lenguaje-inclusivo.

IBARRETXE-ANTUÑANO, I. (2018): "Significado y motivación: la importancia de la corporeización en la semántica", Almeida, A. A. D. y Santos, E. S. (eds.), Linguistica Cognitiva: redes de conhecimento d'aquém e d'além-mar, Salvador: EDUFBA, pp. 37-52.

LLEDÓ, E., CALERO, M. A. \& FORGAS, E. (2004): De mujeres y diccionarios. Evolución de lo femenino en la $22^{a}$ edición del DRAE. Madrid: Instituto de la Mujer. Disponible en https://www. eulalialledo.cat/wp-content/ uploads /2017/02/2004DeMujeresyDiccionariosEvolucionFemenino.pdf.

LLEDÓ, E. (2009): De lengua, diferencia y contexto, Pamplona: Gobierno de Navarra, Departamento de Educación. Disponible en: https://www.eulalialledo.cat/es / publicaciones/sobre-lengua/.

LÓPEZ-CORTÉS, N. (2019): "La interpretación subjetiva de la ambigüedad léxica: una aplicación lexicográfica", LinRed: Lingüística en la red, 17, pp. 1-16. https://doi.org/10.37536/LINRED.2020.XVII.3.

LÓPEZ-CORTÉS, N. (2020a): "El lenguaje será ambiguo o no será: el porqué de la ambigüedad léxica y su estudio desde la evolución del lenguaje", E-AESLA, 6, pp. 117-128.

LÓPEZ-CORTÉS, N. (2020b): "Design of a corpus of stimuli for a psycholinguistic study of lexical ambiguity", Research in Corpus Linguistics, 8(1), pp- 1-16. https://dx.doi.org/10.32714/ ricl.08.01.01.

LORENZO, G. J. \& LONGA, V. M. (2003): Homo Loquens: Biología y evolución del lenguaje, Lugo: Tris Tram.

MENDÍVIL GIRÓ, J. L. (2020): "E1 masculino inclusivo en español", Revista Española de Lingüística, 50, pp. 35-64. http://dx.doi. org/10.31810/RSEL.50.1.2.

MILLER, C. \& SWIFT, K. (1972): "One small step for genkind", New York Times. Disponible en https://www.nytimes. com/1972/04/16/archives / one-small-step-for-genkind-onesmall-step-for-genkind-or-consider.html.

NAVARRO, F. A. (2020): "Covid-19: lenguaje médico en ebullición", Archiletras, 8, pp. 58-65.

OGENVA, A. (en prensa): "A review on gramatical gender acqusition in monolingual Spanish-speaking children", Onomázein. Disponible en: https://www.researchgate. net/profile/Anastasiia_Ogne$\mathrm{va} / \mathrm{publication} / 340886678$.

PIANTADOSI, S. T., TILY, H. \& GIBSON, E. (2012): "The communicative function of ambiguity in language". Cognition, 122(3), pp. 280-291. https://doi.org/10.1016/j. cognition.2011.10.004.

RODRÍGUEZ DÍEZ, B. (2003): "Las marcas en los diccionarios generales de lengua", Estudios humanisticos Filología, 25, pp. 139-157. Disponible en: http://dx.doi. org/10.18002/ehf.v0i25.2691.

SAUSSURE, F. (1987, [1916]): Curso de Lingüística General. Madrid: Alianza Editorial.

STELLA, M., BECKAGE, N. M., BREDE, M. \& DE DOMENICO, M. (2018): "Multiplex model of mental lexicon reveals explosive learning in humans", Scientific Reports, 8, pp. 1-11. https:// doi.org/10.1038/s41598-01820730-5.

SUARDIAZ, D. E. (2002): El sexismo en la lengua española, Zaragoza: Libros Pórtico.

VALERA, N. (2013): Feminismo para principiantes, Barcelona: Penguin Random House. 